\title{
Dirphia Hübner (Lepidoptera, Saturniidae, Hemileucinae): descrição de uma espécie nova do sul do Brasil e da fêmea de $D$. rufescens $F$. Johnson \& Michener
}

\author{
Carlos G. C. Mielke ${ }^{1} \&$ Alfred Moser ${ }^{2}$ \\ 1 Caixa Postal 1206, 84145-000 Carambeí, Paraná, Brasil.E-mail: cmielke1@uol.com.br \\ ${ }_{2}^{2}$ Avenida Rotermund 1045, 93030-000 São Leopoldo, Rio Grande do Sul, Brasil. E-mail: a.moser@ensinger.com.br
}

\begin{abstract}
Dirphia Hübner (Lepidoptera, Saturniidae, Hemileucinae): description of a new species from Southern Brazil and the female of $D$. rufescens $F$. Johnson \& Michener. A new species of Dirphia Hübner, [1819] from Rio Grande do Sul and Santa Catarina, Brazil is described. Closely related to D. sombrero (Le Cerf, 1934), the new species differs by its smaller size and male genitalia (aedeagus bears dorsal vesica and this shows disperse spiculae). The female of Dirphia rufescens F. Johnson \& Michener, 1948 is described for the first time and its geographical distribution is updated.
\end{abstract}

KEY WORDS. Distribution; neotropical; taxonomy.

RESUMO. Uma nova espécie de Dirphia Hübner, [1819] do Rio Grande do Sul e de Santa Catarina, Brasil é descrita. Aproxima-se de D. sombrero (Le Cerf, 1934), mas difere pelo tamanho menor e pela genitália masculina (edeago com vesica dorsal, sendo esta provida de espículas dispersas). A fêmea de Dirphia rufescens $F_{\text {. }}$ Johnson \& Michener, 1948 é descrita pela primeira vez e a sua distribuição atualizada.

PALAVRAS-CHAVE. Distribuição; neotropical; taxonomia.

O gênero Dirphia Hübner, [1819] ocorre desde a Nicarágua até o norte da Argentina e o sul do Brasil (Lemaire 2002). Das aproximadamente 40 espécies pertencentes a este gênero, a metade tem registro em território nacional, sendo sete as espécies que ocorrem na região sul do Brasil: $D$. curitiba Draudt, 1930, D. muscosa Schaus, 1898, D. araucariae E.D. Jones, 1908, D. baroma (Schaus, 1906), D. moderata Bouvier, 1929, D. dolosa Bouvier, 1929 e D. fornax (Druce, 1903).

Aqui se descreve uma nova espécie de Dirphia Hübner [1819], aumentando para oito as espécies sul-brasileiras.

O material estudado pertence às seguintes coleções brasileiras: (CGCM) Coleção Carlos G.C. Mielke, Curitiba, Paraná; (CLAM) Coleção de Lepidoptera Alfred Moser, São Leopoldo, Rio Grande do Sul; (CPAC) Coleção Embrapa Cerrados, Planaltina, Distrito Federal; (MCTP) Museu de Ciências e Tecnologia PUCRS, Pontifícia Universidade Católica do Rio Grande do Sul, Porto Alegre, Rio Grande do Sul; (MNRJ) Museu Nacional, Universidade Federal do Rio de Janeiro, Rio de Janeiro, Rio de Janeiro; (MZUSP) Museu de Zoologia da Universidade de São Paulo, São Paulo, São Paulo; (DZUP) Coleção Entomológica Padre Jesus Santiago Moure, Departamento de Zoologia, Universidade Federal do Paraná, Curitiba, Paraná.

\section{Dirphia riograndensis sp. nov.}

Figs 1-6

Diagnose. Macho (Figs 1-2). Asa anterior $32 \mathrm{~mm}$, envergadura $63 \mathrm{~mm}$ com a margem posterior da asa anterior em ângulo reto com a linha longitudinal do corpo (parátipos: asa anterior 31-35 $\mathrm{mm}$ ). Antena quadripectinada amarelo-palha com 36 artículos. Fronte e palpos labiais marrons escuros. Tórax dorsal e ventralmente cinza escuro com escamas avermelhadas, tegula marrom com a porção distal marrom-avermelhada. Pernas e epífise com o mesmo padrão cromático do tórax; esporões tibiais 0-2-3. Asa anterior medianamente alongada, ápice pouco pronunciado e margem externa levemente convexa; linhas ante e pós-mediais pretas e irregulares, bem marcadas, ladeadas por escamas brancas basal e distalmente, respectivamente; área basal marrom-acizentada com a base marrom-avermelhada; área mediana marrom, estigma branco entre $\mathrm{R}_{5}-\mathrm{M}_{1}$ com um ponto negro no centro; distalmente à linha pós-medial há uma banda marrom seguida de uma faixa preta, uma área sub-marginal clara e a margem marrom. Asa posterior pouco alongada; cinza escuro com o estigma levemente marcado e com a venação marcada distalmente por um marrom-avermelhado. Ventralmente a coloração é uniformemente marrom-avermelhada com os estigmas pretos bem marcados e as linhas pós-mediais cinzas. Abdômen dorsalmente preto, com anéis marrom-avermelhados posteriormente a cada segmento. Tufo anal da mesma cor dos anéis; o oitavo esternito (Fig. 3) é bilobado posteriormente. A genitália (Figs 4-6) apresenta o unco dorsalmente bilobado com uma porção muito esclerotinizada curvada para baixo; transtilha fundida com a valva e com braços laterais pronunciados; valva rudimentar com a porção ventral projetada posteriormente e coberta com 

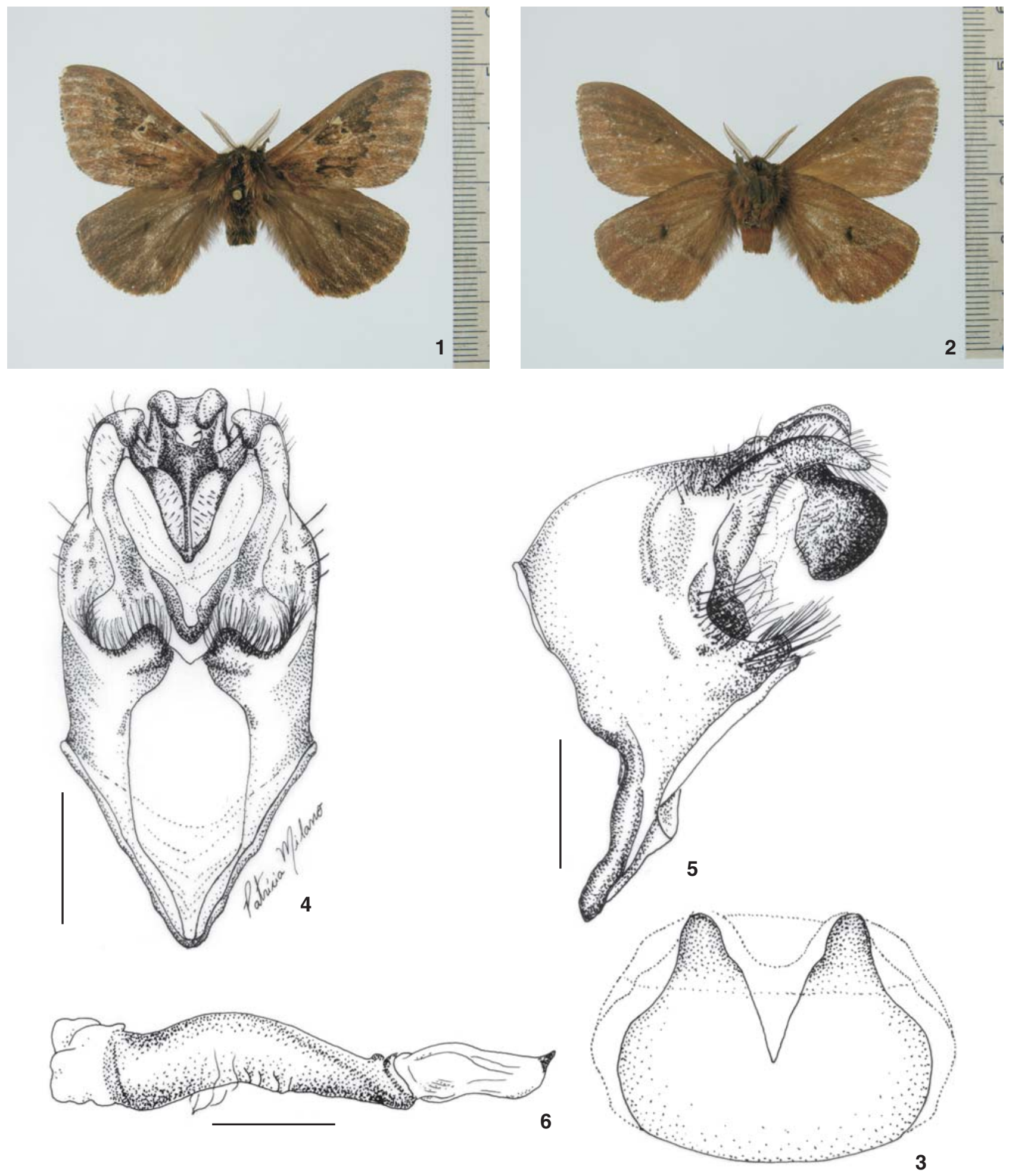

Figures 1-6. Dirphia riograndensis sp. nov., macho: (1) dorsal, (2) ventral; (3) oitavo esternito; (4-6) genitália masculina: (4) vista posterior; (5) vista lateral; (6) edeago, vista lateral. Escala: $1 \mathrm{~mm}$.

Revista Brasileira de Zoologia 24 (2): 319-322, junho 2007 


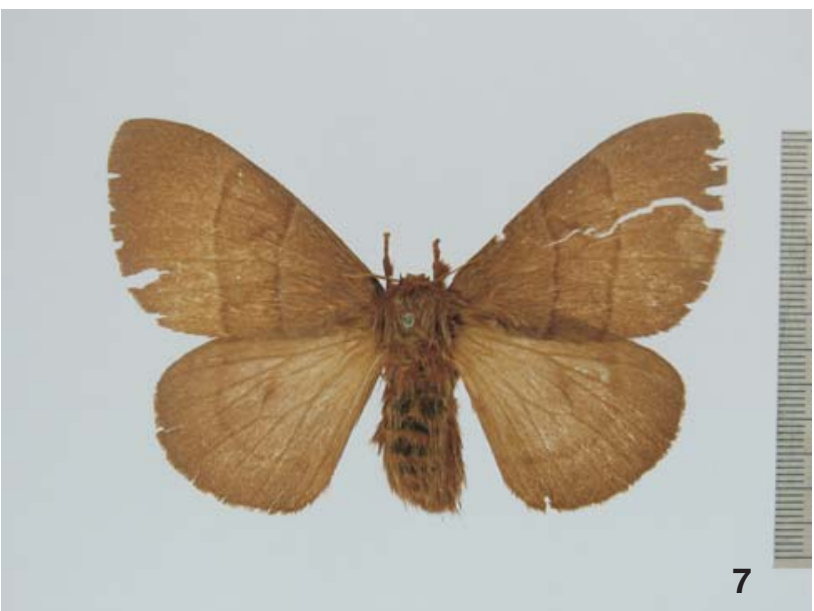

Figures 7-8. Dirphia rufescens, fêmea: (7) dorsal, (8) ventral.

cerdas; projeção anterior do saco triangular; edeago simétrico levemente curvado; bulbo ejaculatório um quinto do comprimento do edeago; vesica dorsal simples com dois terços do comprimento do edeago, apresenta espículas dispersas e pequeno cornuto apical.

Fêmea desconhecida.

Material estudado. Holótipo macho com as seguintes etiquetas: /Holotypus, Dirphia riograndensis C. Mielke \& Moser det. 2006/ Brasil, Rio Grande do Sul, São Francisco de Paula, Rio Santa Cruz, 650 m, 7-8.VI.2005, A. Moser leg./ DZ[UP] 9.717/ Doado pelo autor júnior e depositado na UFPC. Parátipos, 7 machos: 1 macho (CGCM 12.062), Brasil, Santa Catarina, Bom Jardim da Serra, 1500m, 1-4.X.1996, V.O. Becker leg.; 2 machos (CLAM 0107; CGCM 19.732) com os mesmos dados do holótipo; 4 machos (MCTP 15.384; CLAM 0105, 0106; CGCM 19.748) com a mesma localidade e coletor do holótipo, 3-4.VI.2005 (Fig. 9).

Discussão. Dirphia riograndensis sp. nov. aproxima-se de $D$. sombrero Le Cerf, 1934, no entanto se difere pelo tamanho menor, pelo estigma da asa anterior maior e melhor marcado, pelo edeago com vesica dorsal sem concentração de espículas e pela distribuição geográfica. Dirphia riograndensis sp. nov. é endêmica na Serra Geral de Santa Catarina até o Rio Grande do Sul, Brasil.

Ortıcica (1953) quando descreve Diphia dalcyra Oiticica, 1953, sinônimo de Dirphia sombrero, menciona a distribuição desta espécie apenas para os estados de São Paulo e Rio de Janeiro, posteriromente LEMAIRE (2002) confirma esta distribuição.

Etimologia. O nome da espécie é alusiva à localidade tipo, Rio Grande do Sul.

\section{Dirphia rufescens F. Johnson \& Michener, 1948 Figs 7-8}

Dirphia rufescens é conhecida de poucos exemplares. O holótipo foi descrito do estado de Minas Gerais, Brasil, sem maiores detalhes quanto à localidade. LemAire (2002) não conseguiu
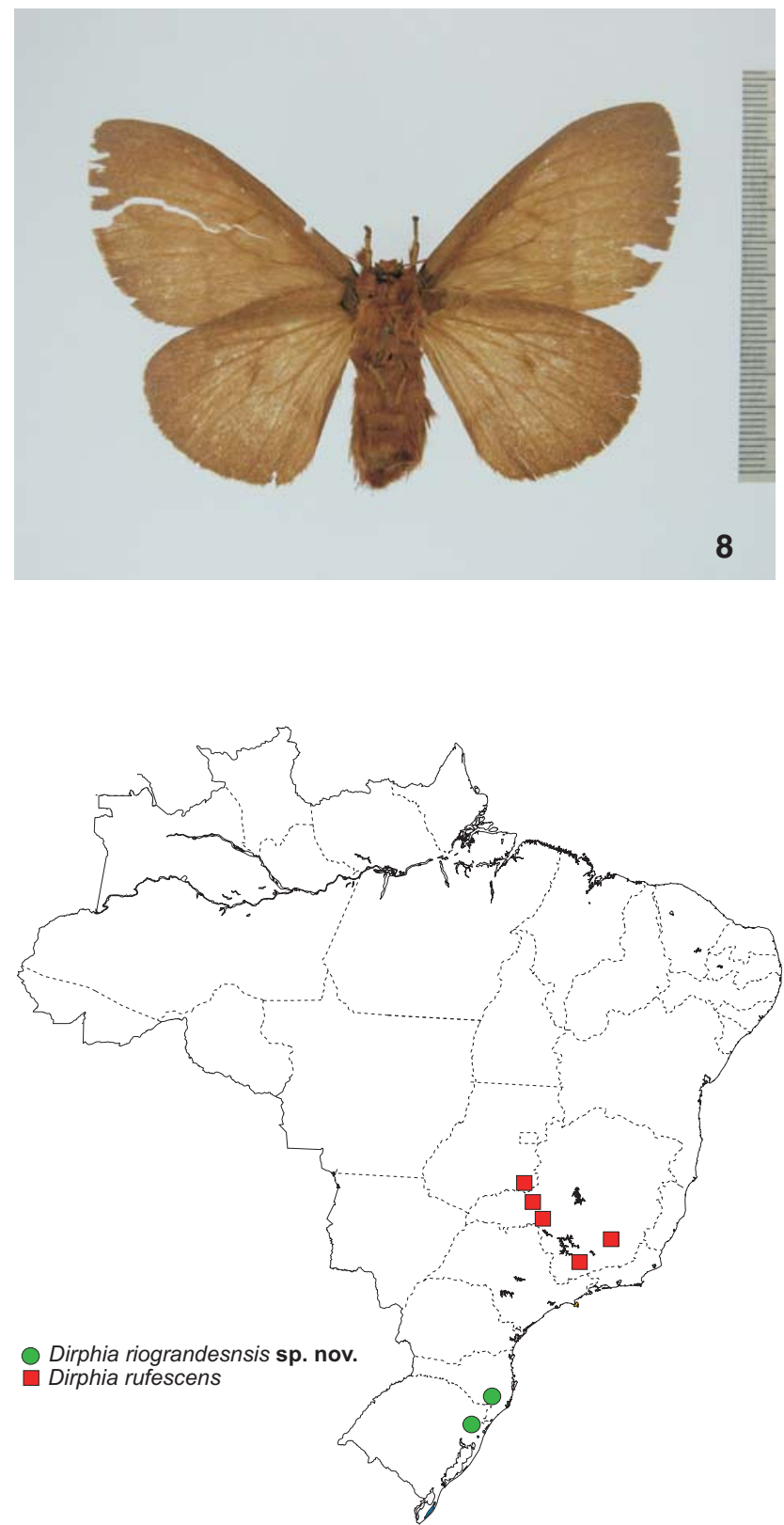

Figure 9. Distribuição geográfica de $D$. riograndensis sp. nov. e $D$. rufescens.

identificar a localidade de Água Suja, provavelmente uma estação de trem no município atual de Pitangui, MG, Brasil o que parece ser razoável visto alguns novos registros mencionados em seguida. A fêmea, até então desconhecida, é descrita a seguir.

Diagnose. Fêmea (Figs 7-8). Asa anterior 47 mm, envergadura $85 \mathrm{~mm}$ com a margem posterior da asa anterior em ângulo reto com a linha longitudinal do corpo. Antena serrada com cerca de 35 artículos. Fronte e palpos labiais castanho- 
avermelhados. Tórax, tégula, pernas e epífise da mesma cor da fronte. Asa anterior com ápice pouco pronunciado e margem externa convexa; linhas ante e pós-mediais castanhas ladeadas por escamas brancas, bem marcadas, basal e posteriormente, respectivamente; área basal castanho-avermelhada mais escura que as áreas mediana e distal; estigma pouco diferenciado entre $R_{5}-M_{1}$. Asa posterior arredondada com o mesmo padrão cromático da asa anterior, área basal mais clara; linha pós-medial marcada e estigma pouco diferenciado. Ventralmente é uniformemente castanho-avermelhada. Abdômen dorsalmente preto, com anéis castanho-avermelhados posteriormente a cada segmento; tufo anal castanho-avermelhado.

Material estudado. Duas fêmeas e quatro machos: BrasiL, Minas Gerais: 1 fêmea (DZUP 9.693), São João Del Rei, 12.XI.1927, B. Raymundo leg., Ex. Col. Gagarin; 1 macho (DZUP 9.712), São João Del Rei, III.1956, Ex. Col. F. Justus Jor.; 1 macho (MNRJ), Araxá; 1 macho (MZUSP), Caxambu. Goiás: 1 fêmea (CPAC 18.272); Catalão, 920 m, X.2001, $17^{\circ} 28^{\prime} \mathrm{S}, 47^{\circ} 20^{\prime} \mathrm{W}$, A. Camargo leg.; 1 macho (CPAC 13.392), Minas Gerais: Iraí de Minas, 950 m, II.1994, S $18^{\circ} 43^{\prime}$ W 47 30 30' (Fig. 9).

\section{AGRADECIMENTOS}

À Patrícia Milano pelos desenhos; a Amabilio Camargo, Alexandre Soares e Marcelo Duarte pelo acesso e suporte na Coleção da Embrapa Cerrados, na Coleção do Museu Nacional e na Coleção do Museu de Zoologia, respectivamente.

\section{REFERÊNCIAS BIBLIOGRÁFICAS}

Le Cerf, F. 1934. Deux saturniodes nouveaux du Muséum de Gèneve. Revue suisse de Zoolgie 41: 263-266.

Lemaire, C. 2002. The Saturniidae of America. Les Saturniidae Americains ( = Attacidae). Hemileucinae. (Goecke \& Evers, Keltern; October 31 $1^{\text {st }}, 2002$, recte December 6, 2002 [data correta de pubicação de acordo com nota pessoal do editor, Mr. Erich Bauer, Keltern]): Part A: [1]-688; Part B: [689]-1388; Part C: col. pls 1-126, ES1-ES14, 143p.

Orticica F.J. 1953. "Dirphia dalcyra", nova espécie (Lepidoptera, Hemileucinae). Revista Brasileira de Biologia 13 (4): 381388.

Recebido em 23.VI.2006; aceito em 28.IV.2007.

Revista Brasileira de Zoologia 24 (2): 319-322, junho 2007 